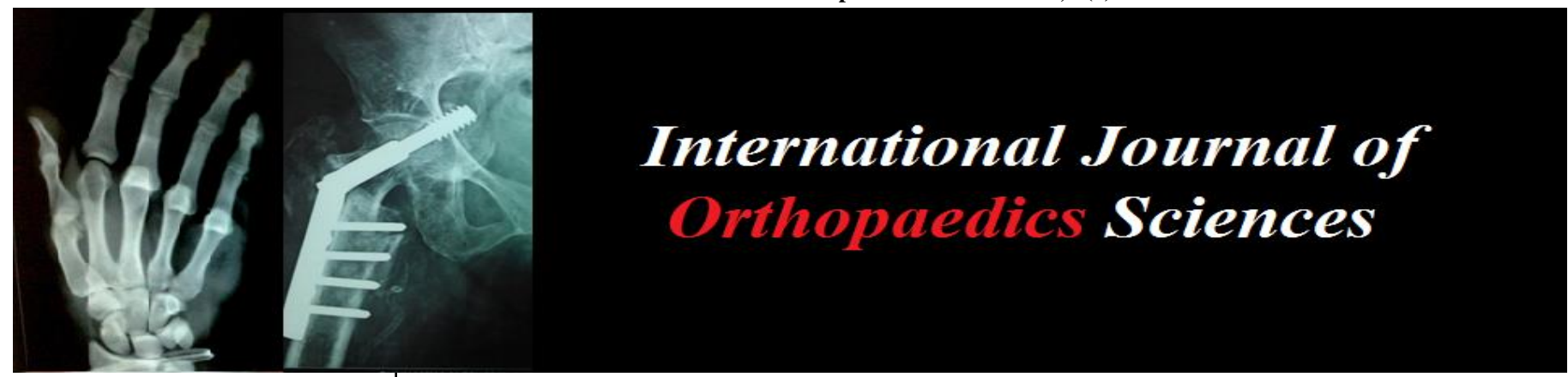

E-ISSN: 2395-1958

P-ISSN: 2706-6630

IJOS 2021; 7(1): 681-683

(C) 2021 IJOS

www.orthopaper.com

Received: 19-10-2020

Accepted: 21-12-2020

Dr. Ramesh Benguluri

MS (Ortho), Asst. Professor,

DCMS, Hyderabad, Telangana,

India

Dr. C. Rahul Reddy

MS (Ortho), Asst. Professor

DCMS, Hyderabad, Telangana,

India

Dr. C Sham Sunder

Professor and Head of

Department of Orthopedics,

DCMS, Hyderabad, Telangana, India

\section{Salvage procedures in post-polio residual paralysis (PPRP) with or without arthritis}

\author{
Dr. Ramesh Benguluri, Dr. C Rahul Reddy and Dr. C Sham Sunder
}

DOI: https://doi.org/10.22271/ortho.2021.v7.i1k.2559

\section{Abstract}

Poliomyelitis is a rare disease at present, but presentation with its sequalae is not uncommon. In this study we are presenting 5 different cases with 5 different deformities in lower limb, who were managed with arthrodesis, tendon transfer, and osteotomies in combination. All the 5 patients were satisfied with their gait and pain relief after surgery compared with pre-operative status. All patients were followed for period of 2 years post operatively, no major complications were encountered. In conclusion, because of gross muscle power compromise replacement surgeries will not give good results in post residual paralysis patients, so salvage procedures definitely improve the performances of patients with painful unstable joints.

Keywords: knee arthrodesis, hamstring transfer, pelvic supportive osteotomy (PSO), grice-green subtalar arthrodesis

\section{Introduction}

Polio though supposed to be extinct now, India constituted over $60 \%$ of all global polio cases as recently as 2009 . The last case of polio was 18 months old baby paralyzed by polio in January 2011. However, in 2014, India was officially declared polio-free, along with the rest of the South-East Asia Region.

The presence of virus in sewage samples collected from Hyderabad has imposed a vital challenge to WHO's March 2014 declaration "India a polio-free nation" ${ }^{[1,2]}$.

While the incidence of new cases has been remarkably reduced, the availability of immunization has no effect on those who already have had the disease ${ }^{[3]}$.

These children are now mostly late teenagers and adults. The treatment of post polio residual deformities is now mostly an adult problem.

Good manual muscle evaluation skills need to be relearned. A muscle usually loses one full grade when transferred. Therefore to be functionally useful a grade of at least 4 is necessary. However, a grade 3 muscle, while unable to provider a useful function after transfer, may be effective in preventing deformity by better balancing forces about a foot or hand ${ }^{[4]}$.

Reconstruction in the lower extremities is somewhat different than in the upper extremities, at least to the extent that in the lower extremities it is more important to have strong muscles proximal ward while in the upper extremities the joints distal ward -wrist, hand and fingers-are the most important ${ }^{[5]}$.

Described are the cases of post polio residual paralysis with various degrees of lower involvement.

\section{Methodology}

This is retrospective study of 5 Patients admitted in teaching Hospital between 2016 -2019.

Aim

To know the efficacy of various salvage procedure in lower limbs with post-polio residual paralysis.

\section{Inclusion criteria}

patients with history of polio myelitis, isolated lower limb involvement with or without arthritis. 


\section{Exclusion criteria}

Neuropathic joints / flail joints of other pathology like MyeloMeningocele (MMC) were excluded.

Post op Patients were monitored for Pain relief and improvement in gait.
Case 1: Flail right knee with arthritis- knee arthrodesis.

A 28 Years old women with arthritis knee with poor quadriceps function, was operated by doing knee arthrodesis, with 5 degree of valgus and 10 degree of flexion. Patient was followed for 10 weeks, and she attained good pain relief with stable knee, able to walk with stick, with no hand knee gait.
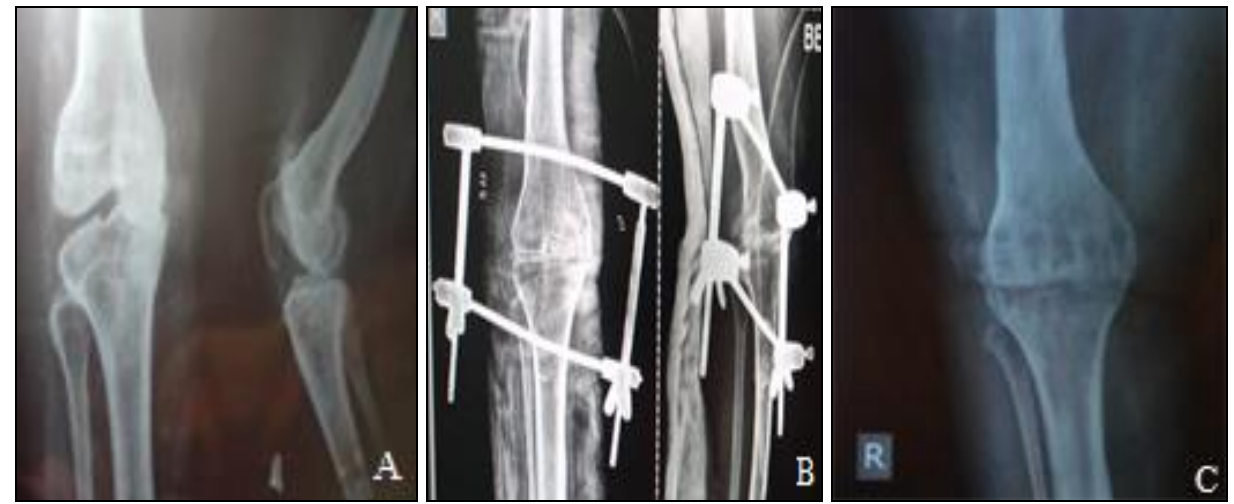

Fig 1A-C, Case 1, A, Pre-op X-ray. B, Immediate Post op X-ray with implants. C, Post op X-ray after implant removal.

Case 2: Left knee quadriceps paralysis-Hamstring transfer. (6)

A 22 years female presented left knee quadriceps power $0 / 5$ and Left hamstrings power $4 / 5$, there is no arthritis of knee and with right knee full extension. Hamstrings transfer was done, medially semi tendinosis and laterally biceps femoris were reinserted over patella creating intra osseous tunnel, above knee cast was given for 6 weeks with 30-degree flexion. Post procedure patient had stable knee, with no hand knee gait, there was extension lag of 20-degree, patient could flex her limb completely. There was 20-degree extension deficit after vigorous physiotherapy.
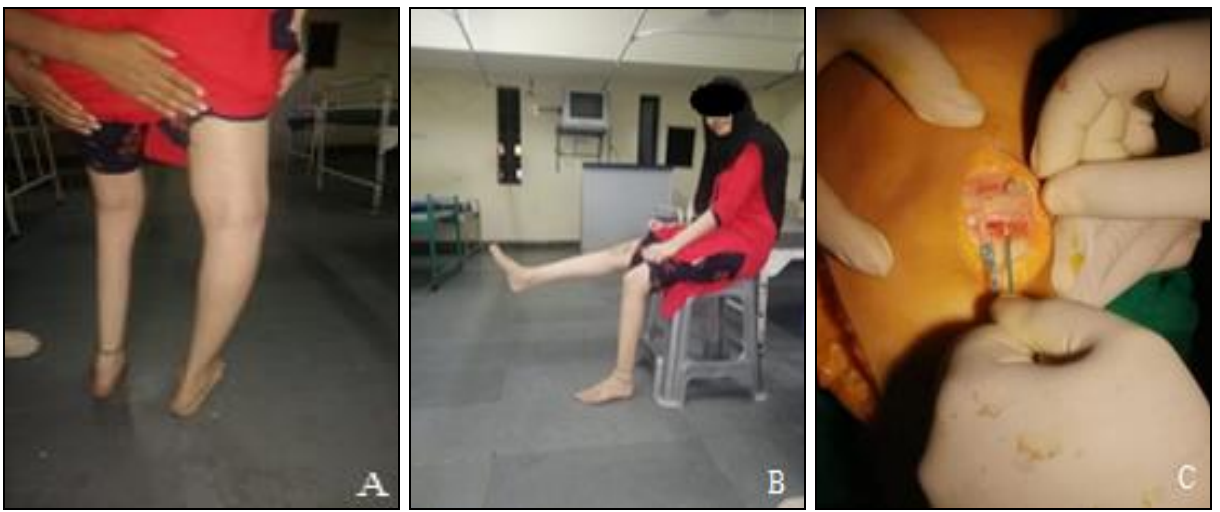

Fig 2: A-C, Case 2, A, Preop in standing, B, Pre-op Left knee quadriceps with zero function, C, Intra op

Case 3: Right hip arthritis-Pelvic supportive osteotomy (PSO).

A 34 Years old man, with arthritis right hip had fixed flexion deformity of 30 degree. He was unable to squat and sit on ground. Pelvic supportive osteotomy (PSO) was done with head of femur excision, valgus osteotomy of proximal femur was done with 40 degree of angulation. In follow up patient had moderately stable hip and pain free limping gait but patient had limb shortening by 4 inches and unable to run and brisk walk, refused for limb lengthening procedure and managed with heel rise footwear.
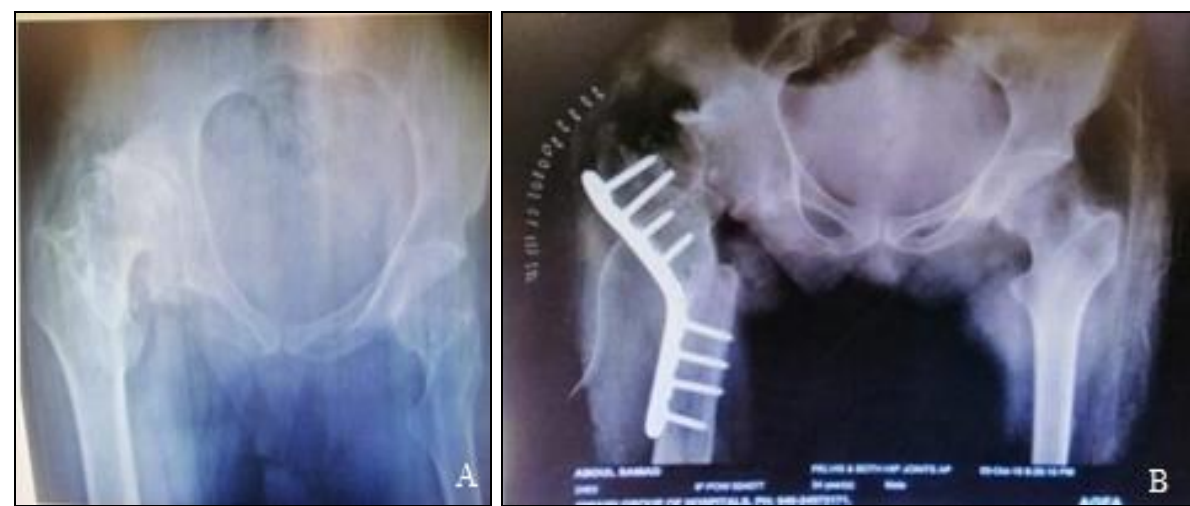

Fig 3: Case 3, A, Pre-op X-ray. B, Immediate Post op X-ray with implants 
Case 4: Calcaneo-valgus deformity -Grice-Green Subtalar arthrodesis.

A 25 years female presented with Calcaneo valgus feet and Subtalar instability with no arthritic changes. sub talar arthrodesis (grice green) was done in lateral approach, sinus tarsi was exposed and trough created, fibular graft was placed (in maximum Varus of sub talar joint) Below knee cast was applied. Post op patient was mobilized after 6 weeks. There was Sub talar joint fusion, patient had stable stance with no valgus at sub talar joint.
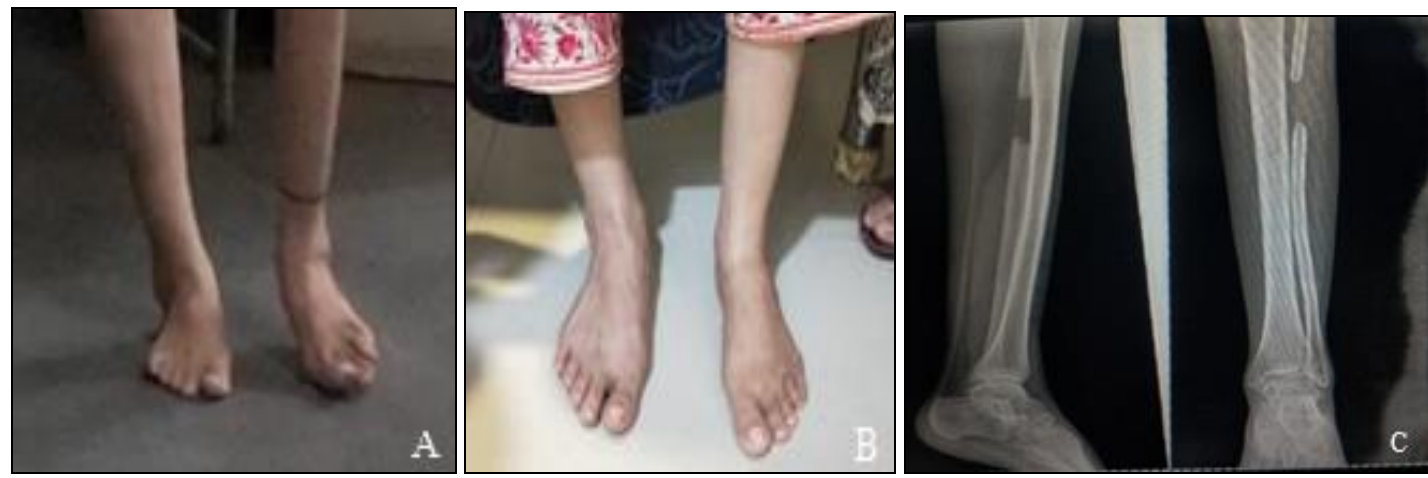

Fig 4: Case 4, A, Pre-op Clinical picture. B, Post op Clinical picture C, Post op X-ray

Case 5: Flail knee with hyper extension deformity corrective osteotomy with hamstrings transfer. (7)

30 years women with hyper-extended knee and hand to knee gait, had poor quadriceps function. Power of quadriceps is $2 / 5$ and that of hamstrings is $4 / 5$. Corrective osteotomy of distal femur and hamstring transfer to patella was done. Post op, patient had improved quadriceps function with power of $4 / 5$, and hand knee gait also improved. Patient could walk without support.
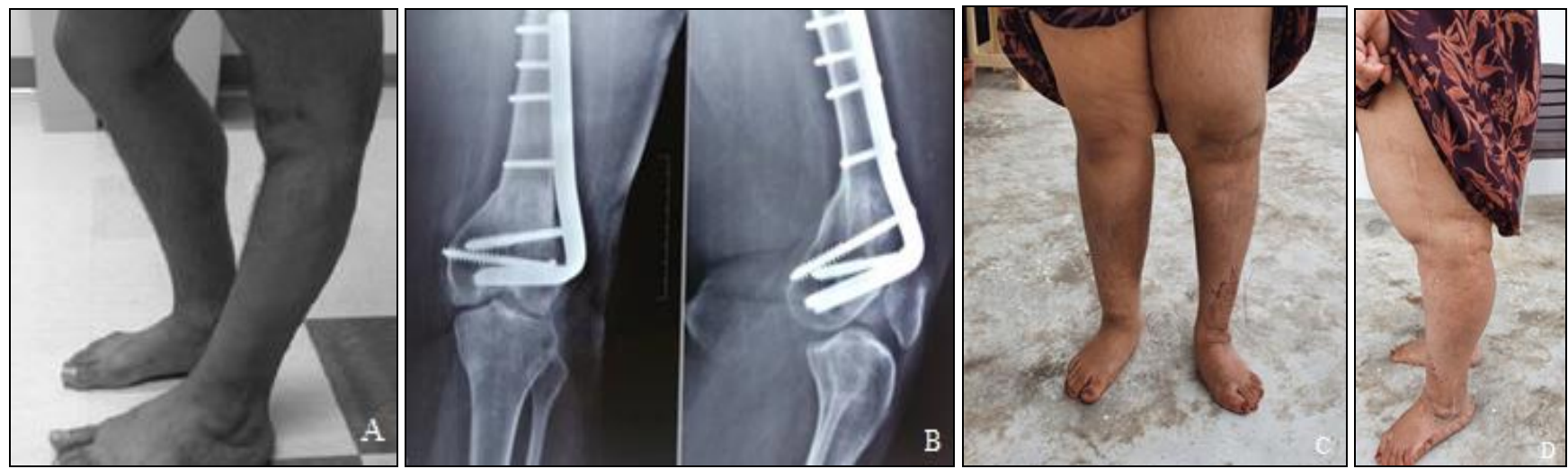

Fig 5: Case 5, A, Pre-op Clinical picture. B, Post op X-ray C, D, Post op Clinical pictures

\section{Results}

In all the above 5 cases arthritic pain improved, muscle imbalance improved, and gait also improved. All the patients had good wound healing with no delay in union of osteotomy or arthrodesis. In all patient's tendon transfer started acting after 2 months with physiotherapy.

\section{Discussion and conclusion}

Though polio is extinct disease now, PPRP are still present in community. The arthritis develops early in PPRP limbs/joints. It is due to altered weight transmission. Arthroplasty is not possible in such cases due to altered anatomy and muscle power. The treatment in arthritic joints in flail limb is either arthrodesis or interposition procedures. The remaining tendons are very important, they need to check cautiously. Tendon transfers are effective treatment options in patient with non-arthritic limb. Though the normal effective activity is not possible but the salvage procedures definitely improves the performances of patients.

\section{References}

1. Donaldson LJ. Eradicating Polio. BMJ 2018;361:k2077.

2. Ruters Health. India to Vaccinate 300,000 Children after Polio Strain Found in Sewage 2016.
3. Hugh $G$ Watts. Orthopedic Techniques in the Management of the Residua of Paralytic Poliomyelitis. Techniques in Orthopaedics 20(2):179-189.

4. Broderick TF, Reidy JA, Barr JS. Tendon transplantations in the lower extremity: A review of end results in poliomyelitis II. Tendon transplantations at the knee. J Bone Joint Surg Am 1952;34:909-914.

5. Brockway A. Surgical treatment for poliomyelitis paralysis; principles of reconstruction of the lower extremities. Calif Med 1957;86(1):37-40

6. Patwa JJ, Bhatt HR, Chouksey S, Patel K. Hamstring transfer for quadriceps paralysis in post polio residual paralysis. Indian J Orthop. 2012;46(5):575-580.

7. O'Malley MP, Pareek A, Reardon PJ, Stuart MJ, Krych AJ. Distal Femoral Osteotomy: Lateral Opening Wedge Technique. Arthrosc Tech 2016;5(4):725-730 